\title{
NOTAS SOBRE LA URSS
}

\author{
Pablo Huerga Melcón \\ Universidad de Oviedo
}

Resumen.- Con motivo del 100 aniversario de la Revolución de Octubre enviamos este ensayo de filosofía de la historia materialista que pretende encajar el fenómeno de la URSS en el marco de las ideas filosóficas y de la inversión sociológica. El artículo ensaya la idea de que el conflicto entre Trotski y Stalin es la encarnación de la inestabilidad ontológica del proyecto en el contexto histórico y en el conflicto ideológico que está recogido en la propia doctrina marxista.

Palabras clave: URSS, Filosofía, Historia, inversión sociológica, inversión teológica, inversión etológica

\section{Notes on the USSR}

Abstract.- On the occasion of the 100th anniversary of the October Revolution, we sent this essay on the philosophy of materialist history that aims to fit the phenomenon of the USSR within the framework of philosophical ideas and sociological investment. The article rehearses the idea that the conflict between Trotsky and Stalin is the embodiment of the ontological instability of the project in the historical context and in the ideological conflict that is included in the Marxist doctrine itself.

Keywords: USSR, Philosophy, History, sociological investment, theological investment, ethological investment

"¿Para qué se hizo la revolución de 1917? Cualesquiera que hayan sido sus consecuencias, se hizo en nombre de la emancipación de los trabajadores de una esclavitud secular. A los hombres, partidos, gobiernos, sistemas y épocas no hay que juzgarlos por lo que no han hecho, sino por lo que han hecho por su época $y$, en las condiciones en que actuaban, por la gente. En este sentido, la reyolución de octubre de 1917 y el régimen social comunista hicieron por amplios sectores de la población mucho más que cualquier revolución de la historia por su propio pueblo. Es una verdad histórica que al final ha sido reconocida en todo el mundo. Por no hablar de la influencia que la revolución y el régimen comunista han tenido en todo el planeta y en la propia evolución de la humanidad." Alexander Zinoviev, La caída del imperio del mal, pág. 168.

\section{Introducción}

Aunque algunos han entendido que lo peor que le pudo pasar al marxismo fue haberse hecho carne en la Rusia zarista, la URSS fue un producto genuino de la filosofía occidental. No el único, desde luego, pero sí uno de sus productos principales, y no precisamente por ese mal agüero goyesco según el cual "el sueño 
de la razón produce monstruos", porque si vamos al caso, entre monstruos se juega la partida de la historia, como dice Doménico Losurdo. Su fracaso, de hecho, es debido a las mismas razones que pusieron en marcha la revolución: cumplir con las aspiraciones más avanzadas y legítimas proclamadas por Occidente, tal y como denuncia el filósofo Alexander Zinoviev; en un caso la realización de la emancipación de la clase obrera y, en otro, la superación de todo tipo de tiranía por la nueva democracia liberal. China ha hecho un recorrido totalmente diverso, $y$ ajeno a occidente, por eso hoy sigue siendo un país comunista a su propio ritmo, demostrando con los hechos que la única manera de gestionar las grandes masas de población del siglo XXI con un mínimo de dignidad pasan por el ejercicio de un poder comunista. No hay duda de que, por mucho que se diga, el comunismo como sistema de gestión de los excedentes productivos es hoy más que nunca una necesidad ineludible.

La revolución de octubre de 1917 es el fruto más genuino de la filosofía desarrollada por Marx y Engels, que promovía un ideal acariciado desde siempre por la filosofía occidental. La idea de perfeccionamiento del hombre y de la sociedad, la aspiración a alcanzar un estatuto verdaderamente humano. El ideal de una vida buena y plena que impregnó desde sus orígenes a la filosofía occidental. Ahora bien, como se sabe, una de las tesis más conocidas de Marx en relación al papel histórico de la filosofía es aquella tesis 11 sobre Feverbach según la cual "los filósofos se han dedicado a interpretar el mundo, de lo que se trata es de cambiarlo". Nuestro ensayo parte de una propuesta de interpretación de esta afirmación de Marx en términos materialistas, para encajar posteriormente en ella la propia realidad de la revolución de octubre y la Unión Soviética. Según nuestra interpretación, al afirmar Marx que los filósofos han interpretado el mundo en vez de cambiarlo no estaría diciendo tanto que la filosofía anteriormente no se hubiera implicado en la transformación de la realidad, porque de hecho a Marx no se le podía escapar que efectivamente la filosofía ha estado siempre involucrada con las transformaciones históricas. Seguramente podríamos entender esta tesis, desde un punto de vista materialista, en este sentido: Que los filósofos han buscado cambiar el Mundo una vez cambiado el propio Hombre. Sin embargo, Marx y el materialismo que define el marxismo, según el cual las condiciones materiales determinan la conciencia, estaría advirtiendo que es necesario primero cambiar el Mundo, las condiciones materiales de existencia, para reformar al Hombre. Lo fundamental, entonces, es que ya no hablamos del Hombre en el sentido trascendental kantiano o cartesiano, sino de los hombres que viven y mueren en la ciudad. Sostenemos, pues, que la filosofía marxista, y por tanto también su producto más genuino, la revolución de octubre, se desarrolla en un contexto ideológico y filosófico en el que ha tenido lugar lo que vamos a llamar la "inversión sociológica".

\section{De la inversión teológica a la inversión sociológica}

1. Utilizando la llamada geometría de las ideas de Gustavo Bueno, tal y como quedó expuesta en obras como Ensayos materialistas, o en La metafísica presocrática, podemos decir que los grandes períodos históricos occidentales han 
estado, digamos, cubiertos por una cúpula ideológica presidida por tres grandes ideas filosóficas que se suceden en el tiempo: la idea de Mundo, la idea de Dios, y la idea de Hombre. El período antiguo hasta la irrupción del Cristianismo en el Imperio Romano está regulado por la idea del Mundo, una idea modulada de diversos modos, desde el problema de la physis en los presocráticos, hasta la idea de átomo de Lucrecio, mucho más elaborada y abstracta. Con el cristianismo y el fin del Imperio Romano se abre un período presidido por la idea de Dios, que cubre toda la época medieval como punto de fuga y referente de toda especulación filosófica y científica, abriendo camino a las nuevas ideas que alimentarán la revolución científica.

El fin del Medievo, desde la perspectiva de la historia de la filosofía, se produce por lo que Bueno llamó en su Ensayo sobre las categorías de la economía política la Inversión Teológica, que consiste fundamentalmente en la transposición al hombre de las notas atribuidas tradicionalmente a Dios, tal y como quedó formulado en la filosofía de Descartes. "Dios ya no es aquello de lo que se habla, sino aquello desde donde se habla del Mundo, etc." La inversión teológica trajo consigo la sustitución de Dios por la idea de Hombre como idea vertebradora del pensamiento filosófico en las dos corrientes paralelas que se abren a través de la filosofía tomista y occamista y, con ello, la atribución al Hombre de las notas de Dios, que es el problema de la Teodicea de Leibniz, por ejemplo. El debate entre Clarke y Leibniz acerca del papel de Dios en el mundo en el contexto de la nueva física podría ser una buena muestra de este nuevo contexto ideológico presidido por una idea de Dios demasiado humana, o por una idea de Hombre que quiere parecerse a Dios hasta identificarse con él.

2. Ahora bien, cuando hablamos del Hombre como idea cupular, es necesario que recuperemos el principio de Protágoras que dice "El hombre es la medida de todas las cosas, de las que son en tanto que son, y de las que no son, en tanto que no son". Porque cuando hablamos de la idea de Hombre como idea nacida de la inversión teológica, necesariamente se nos abren al menos tres vertientes interpretativas que ya desde tiempos de Protágoras es necesario recorrer. En efecto, la afirmación de Protágoras puede entenderse al menos de tres modos principales. El primer modo es aquel según el cual el Hombre se entiende en sentido trascendental; el segundo modo, aquel en el que Hombre se entiende en sentido moral, como expresión de la existencia de países, naciones, clases, pueblos, culturas y civilizaciones; y el tercer modo es aquel en el que el Hombre se entiende en el sentido individual, ético, psicológico, o etológico.

\subsection{El sujeto trascendental}

Si entendemos al Hombre en el sentido universal de la Declaración de los derechos del hombre, tenemos la idea cartesiana y kantiana del racionalismo en la que el Hombre se entiende como Sujeto trascendental, y en la que se enmarca también el ideal ilustrado y la noción de que es el ideal al que debe aspirar todo hombre, por tanto, de aquí procede una visión universalista, racionalista y gnoseológicamente 
optimista según la cual no habría lugar para el relativismo, ni moral ni gnoseológico.

La corriente del Racionalismo cartesiano, por un lado, que abre el camino de Leibniz y Espinosa, donde Dios y hombres se confunden, y por otra parte, la corriente empirista inglesa que partiendo de Descartes trata de legitimar la validez del conocimiento en la vinculación entre el Yo y el Mundo hasta el límite en el que el Yo queda disuelto por así decir en la idea de impresión sensible, tal y como lo propone Hume, alcanzan su síntesis en la Crítica de la razón pura de Kant. Se diría que Hume es el máximo ateísmo con respecto al Yo cartesiano, igual que Tomás de Aquino es el ateísmo aristotélico con respecto al Dios cristiano. No olvidemos que varias de sus tesis fueron condenadas en 1273 por el Obispo Esteban Tempier. Ese ateísmo se manifiesta con respecto al Yo como escepticismo radical y crítico.

Kant sintetiza estas dos corrientes, integrando por un lado la idea de Yo en la figura de la estética trascendetal y las condiciones a priori del conocimiento, y por otro lado la idea de una crítica escéptica al conocimiento que pretende dejar un espacio para Dios, frente a la hybris cartesiana en la que Descartes, el Yo y Dios se confunden hasta identificarse. La realización práctica de la idea de la "reforma del entendimiento" por Espinosa es el ideal ilustrado. Con la llustración, la educación se convierte en el proceso de pefeccionamiento y tracendentalización que habría de permitir la transformación del sujeto empírico en Sujeto trascendental, entendido como la realización de un modelo de Hombre libre de determinaciones concretas que, por supuesto, se encarnará en la Declaración de los derechos del hombre y del ciudadano de la Revolución Francesa, y en el ideal que fundamenta la posterior declaración de los Derechos Humanos: un Hombre abstracto, sin sexo, sin edad, sin religión, sin tamaño, sin tiempo, etc., esto es, un Ego trascendental.

\subsection{La inversión sociológica}

Sin embargo, si entendemos al Hombre en clave sociológica, estaríamos situándonos en el marco de la inversión sociológica que hemos señalado anteriormente, donde el Hombre se entiende siempre como configurado en grupos, clases, pueblos, civilizaciones y culturas. Es seguramente este enfoque el que estaría manejando Protágoras cuando se le interpreta como el padre del relativismo, porque según él cada pueblo, cada ciudad, cada nación se da sus propias leyes, cuya validez depende y está determinada por cada contexto social concreto. Relativismo moral y político que también puede alcanzar al relativismo gnoseológico, aunque en el caso del marxismo, claramente instalado en este marco ideológico, este relativismo es meramente histórico, y por tanto induce a considerar la idea de progreso como una forma de superación de ese relativismo.

A partir de la llustración, y con la irrupción de la Revolución industrial fechada en 1750, se produce la transformación histórica que convierte a esos ideales ilustrados racionalistas del Yo, del Hombre en abstracto, en mera ideología de la clase dominante y emergente que va a capitalizar la Revolución Francesa de 1789: la Burguesía. Y eso es precisamente lo que denuncia la nueva filosofía materialista que se abre camino con Marx y Engels; tampoco son ellos los únicos, porque el asunto 
se va abriendo camino no solamente por la vía de las ideas, sino también por el movimiento obrero que surge en el contexto de la revolución industrial y sobre todo por la filosofía hegeliana y el Idealismo alemán. El Idealismo alemán, al identificar al yo con el estado prusiano estaría ejerciendo una nueva inversión en la cúpula de las ideas hasta ahora y desde la Edad Media presididas por la idea de Hombre. Del Hombre se pasa al Estado y del Estado a las clases sociales, al conflicto y a la complejidad del contexto material.

Así pues, con la nueva filosofía del XIX tiene lugar una nueva inversión ideológica que llamamos, en paralelismo con la inversión teológica, la Inversión sociológica, en virtud de la cual el Hombre ya no será más el Sujeto trascendental kantiano, sino las figuras que genera la organización existencial de los hombres en la historia: las naciones, las culturas, las civilizaciones, o las clases sociales. Ramón Valls Plana lo señaló en un libro convenientemente titulado Del yo al nosotros. Y Marx, al hacer la inversión del Idealismo alemán, ya estableció que son las condiciones materiales y no las condiciones a priori de nuestro conocimiento, las que conforman nuestra conciencia, según aquella célebre fórmula de "darle la vuelta a Hegel"; dejando así abierto el camino para entender que siendo esas condiciones materiales diversas, así también las conciencias de los hombres lo serán, por la misma razón. No hay pues una conciencia trascendental detrás de todo hombre concreto, pero tampoco un espíritu, raza, o condición innata particular, ninguna condición a priori de cada pueblo que define la superioridad de unos sobre otros, sino un contexto material objetivo histórico que conforma la conciencia de cada individuo particular y lo integra en un determinado contexto social.

Hasta qué punto queda conformada la conciencia por el contexto material vendrá delimitado por aquello que podemos considerar precisamente como lo constitutivo de ese contexto material. En este sentido la filosofía soviética hizo aportaciones particulares, y precisamente uno de sus principales ideólogos, Stalin, puso de manifiesto que también el idioma forma parte de la base material, frente a las tesis de Marr que estaban en boga entonces. Por tanto, la discusión filosófica acerca de lo que puede considerarse constitutivo material de una época, o de una sociedad, determinará el alcance de la crítica de la conciencia.

Y si en el marxismo esas condiciones servían aun para erigir una historia en fases en donde esas condiciones materiales se podrían interpretar de modo histórico-trascendental puesto que de algún modo estarían definiendo cada una de ellas toda una época histórica universal, el materialismo tenía ahora abierto el camino para discriminar a escala no trascendental, sino fenomenológica y sociológica, y no sólo histórica, cada conciencia, cada grupo social, cada nación y cada región. El relativismo sociológico es pues una consecuencia necesaria del análisis marxista de la realidad material -como señala E. H. Carr; quizá únicamente matizado por la idea de progreso, como cuando decía el anarquista Proudhom, "Niego todo absoluto. Yo creo en el progreso". En efecto, el relativismo sociológico no tiene por qué ser solidario de un relativismo gnoseológico, puesto que al fin y al cabo, también la Unión Soviética, y el propio Marx, postularon la tesis radical de que las ciencias son parte del entramado estructural de una sociedad, una fuerza productiva, y por tanto, conformadora de la conciencia; amén de la idea de que 
la historia supone un proceso de perfeccionamiento del hombre, tal y como viene establecido por la idea de Progreso; pero, como dice Proudhom, se trataría de un progreso sin fin, sin absoluto.

Las nuevas ciencias sociales y la propia expansión iniciada por España y lvego por los colonialismos depredadores, abrieron el camino a la sociología del conocimiento que ha llegado incluso a las cimas del relativismo radical que vendría a ser como el ateísmo medieval o el empirismo moderno: una forma errónea de llevar adelante los nuevos argumentos. Errónea pero quizá necesaria e inevitable para rellenar los nuevos horizontes del análisis lógico filosófico.

Pero también, visto desde la perspectiva materialista abierta por el marxismo, se puede entender claramente que el relativismo cultural, por ejemplo, es propio de los imperios depredadores, y no sólo un ideal irenista rusoniano, sino la forma misma de operar de los imperios depredadores que respetando cínicamente las diferentes culturas contribuyen a su condena civilizatoria, dejándolos al albur de sus costumbres retrógradas o de su atraso cultural; mientras que la postura del imperio español civilizatorio, como la de otros imperios como el soviético, precisamente, o el romano, dan por hecho que todos los hombres, independientemente de su cultura, deben aspirar a un mismo ideal humano y deben ser emancipados, pues la emancipación supone el rechazo de cualquier relativismo perverso. Cuando Todorov denuncia a los españoles por bautizar a los indios, está cometiendo un acto de cinismo que sólo se permite con España por el respaldo de la leyenda negra, esto es, por el apoyo mayoritario de una especie de consenso ideológico llamado pensamiento único; pero verdaderamente bautizarlos, enseñarles español, codificar sus propias lenguas y culturas mezclarse con ellos, construir caminos, ciudades, universidades, hospitales e iglesias, civilizar como hicieron los españoles, o los soviéticos en sus respectivos territorios, es un acto de piedad, de generosidad, y de civilización absolutamente digno y honorable, pero también es una expresión del ejercicio de una visión materialista de la realidad. La perversión procede de la crítica relativista y escéptica, nihilista y radical -filosóficamente idealista- que promociona el nihilismo del occidente neoliberal, en cuyas fronteras marítimas mueren miles y miles de seres humanos a los que previamente hemos juzgado indignos de vivir bajo regímenes malignos por lo que los hemos destruido con nuestros aviones de la OTAN.

\subsection{El fin del hombre. La inversión etológica}

Pero cabe aún una tercera perspectiva sobre el Hombre, aquella en la que el Hombre se interpreta de modo individual, por tanto, reducido a su condición psicológica y etológica, que es la que define lo que hemos denominado la inversión etológica en la que estamos en efecto actualmente envueltos y en la que se ha procedido a atomizar a la sociedad y disolverla en una enmarañada confusión de pasiones y voluntades, de intereses particulares, de egoísmos racionales, de individualismo egoísta: es el paraíso del egoísmo capitalista liberal, donde importa más la vida de mi mascota que la del vecino, etc.

Toda la filosofía occidental es expresión de esta inversión sociológica que se 
extiende por el siglo XX arrasando con los intentos ya puramente ideológicos por sostener al idealismo kantiano y que perdura y encuentra su mayor acomodo en el siglo XXI. El fin de los grandes relatos, la postmodernidad, la filosofía analítica, la muerte de Dios, todo contribuye a disolver el yo como Sujeto en el sujeto líquido, consumidor, ciborg, etc. Toda la tecnofilosofía anglosajona que busca dar cabida ontológica al robot destruyendo la idea de yo sobre argumentos empíricos y científicos, está caminando por la senda de la inversión sociológica que desemboca en el ideal de la democracia liberal, y el relativismo ontológico radical y el dominio universal de las tecnologías de manipulación social.

El individualismo que de alguna manera suele atribuirse al pensamiento anterior a lo que hemos llamado la "inversión sociológica" parte, sin embargo, del principio de la ecualización absoluta y sistemática de los individuos en ese Yo con mayúsculas trascendental kantiano. Sin embargo, después de la "rebelión de las masas" arribamos quizá a una nueva época, una nueva inversión que ya no es teológica, ni sociológica, sino etológica. Del yo pasamos al estado, la clase social, la cultura, la civilización, y de aquí desembocamos en la idea de individuo particular que es portador particular de todo el Ser, donde la voluntad se confunde con el deseo.

Se trata en definitiva del tema del fin del hombre. La expectativa creada por la revolución de octubre obligó a Occidente a reorientar sus planes no hacia el ideal ilustrado de emancipación y perfeccionamiento del Hombre, porque ese ideal lo encarnará siempre el socialismo, sino más bien hacia la aniquilación del Hombre. ¿Cómo? Sustituyendo ese ideal de Hombre total, por el ideal de la satisfacción inmediata de sus ansiedades etológicas. En vez del Hombre ético, el capitalismo ha entendido que las aspiraciones etológicas recurrentes en la especie humana son el mejor camino para su domesticación. Ideales de felicidad, sentimientos, emociones, han debilitado al Hombre, han demolido su fortaleza moral, sus valores humanos; dejándolo preparado para el cumplimiento del programa sistemático de la satisfacción inmediata por el consumo. El sujeto consumidor es una forma de reducción del ideal del Hombre clásico, por su equalizacion zoológica y etológica con el resto de los animales, abundando además en la aceptación resignada de los principios etológicos que guían y presiden la vida animal: sálvese quien pueda, el pez grande come al chico, la selección natural, y en definitiva, los principios del darwinismo social. Los procesos sistemáticos dirigidos por el FMl a favor de la privatización de los servicios públicos son consecuencia inmediata de estos ideales, por ello, el enfermo se convierte en cliente, etc.

Una vez establecido, y regulado por el desarrollo de las nuevas tecnologías, capaces de monitorizar e incluso de digitalizar, ese aspecto zoomórfico de nuestra conducta ancestral y etológica librada definitivamente de la presión civilizatoria y moldeadora de la educación, se pueden ir sustituyendo por equalización los hombres por máquinas sin ningún problema, dando por fin el salto al ideal de robotización del hombre que defiende por ejemplo Ray Kurtzweil o el propietario de Facebook. Aspiran a una nueva Humanidad en vez de atender a los problemas del Hombre. Lo último será que la tecnofilosofía anglosajona descubra por radicalización crítica que la identidad humana no existe más allá del Test de Turing. El Hombre sin horizontes, sin sacrificio, sin proyecto, puede ahora ser sustituido por 
las máquinas de Turing. De hecho, entre los aspirantes a fabricar androides, personajes hoy admirados y reverenciados como gurús, aunque quizá sería mejor meterlos entre rejas, su principal preocupación radica en determinar los rasgos diferenciales que definirán, según ellos, el estándar humano para la construcción industrial del nuevo hombre mecánico.

Creo que las posibilidades lógicas de la inversión sociológica se han agotado, hemos descubierto al hombre disuelto en la masa y hemos relativizado el yo en todas las vertientes, de modo que prácticamente la última frontera: el cerebro, está ya sometida al control tecnológico de la ingeniería informática. Así pues, a golpe de transformaciones científicas y tecnológicas, tal y como las anunciaba Radovan Richta, pero liberadas radicalmente de cualquier control político y emancipadas de cualquier sospecha, en la medida en que hemos asumido ya toda sospecha posible, podemos decir que con la irrupción de la ingeniería informática se ha abierto el camino a una nueva idea cupular de la reflexión filosófica que sustituirá por inversión la sociedad, como ésta sustituyó al hombre, éste a Dios, y Dios al Mundo. De la inversión sociológica, combinada con la revolución cibernética ha derivado la era de los Big Data donde nuevos modos de vida nos acechan. Horizonfes en los que el propio sujeto se desvanece, al comprender todos los mecanismos raciones que derivan en la toma de decisiones, de modo tal que ya es prácticamente posible dominar tecnológicamente sus decisiones, así por tanto esas decisiones pierden su sentido. Es la era leibniziana en la que el cálculo operacional y propositivo determinará más allá de nuestra voluntad lo que verdaderamente nos conviene (se dice: "la intuición es poética, los big data precisos"). Y no será un gran hermano dictatorial, sino la tecnología más neutral y aséptica, y el hombre, sin voluntad efectiva se disuelve como un factor más del cálculo cibernético. También cabe la posibilidad de que en esa nueva era que empieza, deje de ser necesario, como pretendía Leibniz, toda especulación filosófica, inútil, o simplemente redundante. Aunque mucho me temo que esta conclusión también puede entenderse como una conclusión posible lógicamente, pero absurda desde el punto de vista filosófico.

\section{El lugar de la Unión Soviética en el contexto de la Inversión Sociológica}

Ahora, ¿qué ha significado la revolución de Octubre y cuál ha sido su papel histórico en el marco general filosófico que acabamos de esbozar?

1. Ante todo, hay que reconocer que es un movimiento revolucionario de clara estirpe filosófica, esto es: sin el materialismo histórico y la reflexión llevada a cabo durante el siglo XIX por los filósofos marxistas, incluidos los rusos, populistas como Hertzen, o marxistas como Plejanov, la revolución de Octubre no sería lo que fue. Su máximo líder, Lenin, dedicó su vida a la reflexión filosófica y en su acción está entreverado todo su pensamiento filosófico. Pero también Stalin ejercitó un trabajo filosófico incesante y sorprendente. La cosa posteriormente decayó: todos recuerdan la anécdota de Malenkov, que nombrado secretario del partido solicitó que su despacho fuera rellenado de libros de filosofía para aparentar lo que no era. 
Esto lo cuentan Roy y Zhores Medvedev en su monografía sobre Stalin. A Gorbachóv no le hizo falta porque su mujer se dedicaba ya a la filosofía.

Como tal, la revolución alcanzó el máximo punto posible en esa nueva idea cupular que es la sociedad, el Estado, como hemos dicho. Porque la inversión sociológica definida por Marx supone que es necesario transformar las condiciones materiales de existencia para transformar al Hombre y su conciencia, haciendo de él una conciencia no alienada, liberada de las contradicciones y supremamente humana, sintetizando todos los ideales emancipadores desde Heráclito y Platón, pasando por el Cristianismo y ta llustración. La revolución es lo primero. El pensamiento marxista se convirtió con la revolución en la doctrina oficial de la Unión Soviética, el Diamat, su ideario y su cosmovisión, su ideología. Se estudiaba en las escuelas y se practicaba en toda situación concebible, por más pintoresca que fuera. Como doctrina, hay que entenderlo, por ejemplo, como la doctrina católica en el Imperio español, esto es, como un ideal de vida que rige a los individuos y orienta su existencia sobre el que forjar la personalidad individual y la trayectoria vital.

Como doctrina filosófica enfrentada al modelo capitalista que precisamente con esa revolución acaba adquiriendo un nítido perfil, comienza a generar en Occidente todo tipo de reacciones filosóficas: Escuela de Fráncfort, el marxismo crítico, el anarquismo, el individualismo, el pragmatismo, el existencialismo, la filosofía analítica, el positivismo, etc. Todos los movimientos filosóficos del siglo XX nacieron en dialéctica contra el marxismo soviético, incluso como en el caso del marxismo critico de la Escuela de Francfort, partiendo de sus propios principios filosóficos, ejercitando una defensa radical del individualismo liberal, y a todos los movimientos filosóficos, y a todas las metodologías de las ciencias humanas dio cumplida respuesta.

La segunda mitad del siglo XX vio cómo el marxismo se convertía en metodología de la Sociología, de la Historia, de la Psicología, de la Antropología; y en todas estas nuevas disciplinas filosóficas, Ełología, Etnología, etc., ofreció magníficos resultados y sorprendentes e inolvidables obras maestras. En todos estos campos gnoseológicos el marxismo floreció con la misma fuerza con la que la URSS se imponía en el panorama internacional en el campo de las ciencias, las tecnologías y las artes. Esto no se puede discutir.

En general, podemos decir, desde las coordenadas de la Teoría del cierre categorial de Gustavo Bueno, que el marxismo encontró una forma de aproximación a las ciencias humanas con la pretensión de elevarlas a su mayor grado de cientificidad, como era preceptivo de su propia posición según la cual la revolución de Octubre estaría respondiendo a una teoría científica de la sociedad consignada en la disciplina del materialismo histórico, como metodología científica de la historia, la sociología, etc. El enfoque marxista -o materialista en general, porque muchos autores materialistas quisieron salirse del corsé ideológico político que lo envolvía, autores americanos como Marvin Harris, por ejemplo-, buscaba regresar a una perspectiva metodológica a-operatoria, y particularmente, $\| l_{2}$, es decir, metodologías que progresan hacia contextos envolventes de las operaciones humanas, pero no genéricos, sino específicos, en crítica constante 
con las tesis reduccionistas $\| a_{1}$, genéricas, que venían representadas, por ejemplo, por el darvinismo social, etc. De modo que es necesario señalar el papel de crítica sistemática de los reduccionismos a-operatorios ejercitados por las corrientes metodológicas que amparándose en una posición positivista de la ciencia, extraían conclusiones claramente reaccionarias y reduccionistas en el ámbito político e ideológico. Me refiero por ejemplo al darvinismo social, que fue uno de los frentes abiertos siempre por el materialismo marxista, ya desde las cartas de Marx en las que denunciaba el aspecto ideológico de la teoría de la evolución de Darwin, pero también al economicismo, a la sociobiología, etc. Seguramente las metodologías genéricas, reduccionistas, están en mayor consonancia ideológica con el individualismo liberal, mientras que las estructuralistas se mueven mejor en contextos específicos envolventes como los grupos sociales, las clases, las culturas, etc. Se trata de la dialéctica entre un horizonte personal frente a un horizonte impersonal de esos contextos que ensayó Gustavo Bueno en sus ensayos sobre las ciencias humanas en su Teoría el cierre categorial.

\section{La dialéctica de estados y la dialéctica de clases}

Pero todas estas críticas filosóficas deben ser vistas no bajo el aspecto puramente lógico del debate de ideas, sino, por supuesto, desde la perspectiva abierta por el análisis materialista que apunta al origen de las ideas en el contexto material. Ahora bien, entender este debate filosófico solamente desde la perspectiva de la lucha de clases y, por ejemplo, la reducción de las ideas filosóficas a la dialéctica de clases, como doctrina burguesa no puede explicar el despliegue y las consecuencias objetivas históricas de dicha revolución. Al contrario, tanto la conformación de la ideología materialista soviética como la de sus antagonistas ideologías burguesas occidentales solo se pueden explicar por el contexto de lo que llama Gustavo Bueno la dialéctica de Estados, y el conflicto generado por sus respectivas fuerzas y poderes. La URSS se conformó como un estado dirigido por la dictadura del proletariado y pronto comenzó a entender la necesidad de fortalecer sus fronteras y ampliarlas todo lo necesario para poder llevar adelante aquellos ideales políticos emancipatorios. Desde el minuto 0 de la revolución se vio claramente que el conflicto subyacente era también un conflicto de estados, como prueba la firma del Tratado de paz de Brest-Litovsk. E. H. Carr, por ejemplo, en su precioso libro The Soviet Impact on the Western World, señala que efectivamente:

"It cant seriously be questioned that security is, and will remain for some time to come, the predominante motive of Soviet policy in Europe. The bitterness caused by the attacks launched on Soviet Russia from the west in the first years of regime has been revive and intensificad by the German invasión. For twenty-five years the queso oír security has gone on. It has been pursued by different methods." (pág. 110-111).

El gran cisma político que se desató en los años veinte en la URSS entre Stalin y 
Trotski procede de la persistencia de la dialéctica de estados, y es el contexto que explica, sin duda, la reorientación general de la Unión Soviética y todos los problemas que se suscitaron durante los años treinta, particularmente, las llamadas purgas de Stalin. Pero esta dialéctica, más allá de las circunstancias políticas particulares que suscitaron y que dieron lugar a una insurrección general dentro de los propios bolcheviques, como ha explicado magistralmente Doménico Losurdo, es la expresión de la dialéctica entre la segunda acepción del Hombre entendido sociológicamente, y la tendencia hacia la tercera figura del Hombre entendido como individuo inalienable, que viene expresada en las posturas más anarquizantes y antiestatalistas que se ampararon en el troskismo en las corrientes marxistas, y el marxismo occidental, sobre todo la escuela de Fráncfort, con la incorporación del Psicoanálisis. Todas ellas tienen en común la negación radical de la dialéctica de estados como contexto de la lucha de clases, haciendo alarde de lo que Stalin consideraba transformar las enseñanzas de Marx y Engels en un dogma y una vacua escolástica (Losurdo, pág. 79). En este sentido, Stalin se preguntaba:

"¿Se conservará entre nosotros el Estado también durante el comunismo? Sí, se conservará, si no es liquidado el acoso capitalista, si no se elimina el peligro de agresiones armadas del exterior" (citado en Losurdo, pág. 80).

En efecto, la Primera Guerra Mundial se transformó inmediatamente en una guerra de invasión contra la URSS comandada por una coalición de países europeos que finalmente fueron derrotados. El fortalecimiento de las fronteras, junto con el fortalecimiento del poder popular, eran esenciales. Pero, además, la URSS, precisamente sobre la base del análisis llevado a cabo por Marx en El Capital, puso en práctica otro de los procesos más esencialmente materialistas y ahora mismo universalmente aceptado: el fortalecimiento de la capa basal del estado, que es el elemento clave de la doctrina del materialismo histórico. Porque es ahí, en esas condiciones materiales de existencia, donde se dirime la conformación de la nueva conciencia soviética. Este proceso corresponde con lo que Stalin identifica como la tercera función que debe cumplir el estado socialista, que es, además, aquella en la que se hace evidente que el comunismo hace imposible la eliminación definitiva del Estado, como pretendían sus contrincantes amparándose en la letra de Marx: "el trabajo de organización económica y el trabajo cultural y educativo de los órganos de nuestro Estado" con el "fin de desarrollar los gérmenes de la nueva economía socialista, y de reeducar a los hombres en el espíritu del socialismo". Y así lo reconoce en el informe al XVIII Congreso del PCUS:

\footnotetext{
"Ahora la tarea fundamental de nuestro Estado, dentro del país, consiste en un trabajo pacífico de organización económica, en un trabajo cultural y educativo". "La función de la represión ha sido sustituida por la función de salvaguarda de la propiedad socialista de los ladrones y de aquellos que derrochen el patrimonio del pueblo". (Citado en Losurdo, pag. 79 y 80.)
} 
Lógicamente, las críticas a Stalin, en su doctrina del socialismo en un solo país, iban a llenarse de lamentos contra la burocracia, y lo que luego se llamó la "nomenklatura"; críticas todas ellas alimentadas y cada vez más universalmente articuladas por una ideología indefinida e indeterminada contra el Estado, que es la ideología marxista que cándidamente impregna el pensamiento occidental y que irá poco a poco radicalizándose contra la URSS como "cárcel de pueblos", y cosas por el estilo. Esta misma dialéctica está presente en los conflictos entre los partidos llamados de izquierdas en España, todos ellos arrastrados por la cuestión de la eliminación del Estado, y está presente en el gran debate filosófico protagonizado por Manuel Sacristán y Gustavo Bueno en torno al papel de la Filosofía, como hemos señalado en un artículo dedicado al tema.

3. No vamos a entrar en un análisis exhaustivo de los procesos históricos concretos por los que tuvo que transitar la URSS en la transformación de su capa basal, pero vamos a decir lo que considero esencial del asunto. Lo que me parece fundamental de este proceso es lo que autores como Trotski, Modest Yosofovich Rubinstein, Bujarin, Plejanov, o el propio Lenin dicen insistentemente, y es lo que dio el éxito a Stalin. Se trata de una idea que procede del núcleo esencial de la crítica marxista. Nos referimos a la idea de Producción; idea que está detrás de toda la ontología materialista en general. Según esta idea, lo que nos conforma como hombres sacándonos del ostracismo del "dominio de la naturaleza" es precisamente la acumulación objetiva del excedente de producción. Lo que los marxistas denuncian y defienden tomando como referencia El Capital de Marx es la necesidad de gestionar racionalmente el excedente de la producción humana. La acumulación objetiva del capital es lo que nos sacó del estado natural, y esa característica de la producción que está enraizada y exponencialmente amplificada por la intervención y el uso sistemático de la técnica, debe ser racionalmente gestionada para garantizar la igualdad, y la justicia social.

El concepto de dictadura del proletariado tiene ese preciso sentido. (Debemos tener en cuenta que aunque la expresión "dictadura" ya lo echa todo a perder, autores como E. H. Carr lo consideraban como un verdadero y legítimo modelo democrático, lo que se llamó Democracias populares, pero esto ya no interesa a nadie.) En todo caso, la necesidad de establecer un procedimiento de redistribución del excedente generado en todas las esferas de la producción humana, un excedente que conforma ontológicamente al hombre, capaz de generar estructuras que le sobreviven en el tiempo, incluido cosas como el cambio climático o los vertederos infinitos de Ghana, hace at Estado imprescindible. Este excedente, dejado a sí mismo, se despilfarra y alimenta naturalmente la desigualdad y la lucha de clases. El Estado, en tanto que institución guiada por la dictadura del proletariado, debe establecer los procedimientos necesarios para la redistribución equitativa del excedente productivo. Por tanto, el Estado es una necesidad objetiva derivada de la propia idea de producción, y no una superestructura superable en el tiempo, etc. La URSS, con su doctrina del socialismo en un solo país, dejó de lado esas ideas equivocadas acerca de la desaparición del Estado y se centró en su fortalecimiento. Sólo en el Estado se genera la lucha de 
clases, y sólo desde el Estado se puede gestionar esa lucha de clases. De hecho, E. H. Carr señala como el principal impacto de la URSS en Occidente en materia económica la planificación sistemática de la economía productiva del país:

"Certainly, if "we are all planners now", this is largely the result, conscious or unconscious, of the impact of Soviet practice and Soviet achievement." (pág. 20). Pero advierte: "The Soviet Union has been generally accepted as the creator of contemporary "planning", not so much because it first started planning or even because it did it more thoroughly that anyone else, but because it has most successfully combined the national and social aspects of planning into a single policy." (p. 27).

Carr incluso señala que aunque Keynes seguramente alcanzó sus propias conclusiones de modo independiente, es evidente que la Unión Soviética ya estaba aplicando esas doctrinas que luego serían ineludibles para Occidente.

Este principio llevado a sus últimas consecuencias hizo que la URSS pasara de ser un país más o menos desarrollado junto con amplios territorios instalados en el Neolítico, en la segunda potencia mundial, capaz de hacer sombra a países tradicionalmente más desarrollados en su capa basal, como Alemania, Gran Bretaña, o EEUU. La amenaza del comunismo iba pareja a la lucha de clases como conflicto instalado ya en todas las sociedades que habían llevado adelante la Revolución industrial, y esa amenaza tenía muchos frentes; no sólo el productivo, también el ideológico, por cuanto la URSS arrasó con todas las tradiciones sociales que de algún modo sustentaban el conflicto de clases en el mundo ruso.

Debemos tener en cuenta que efectivamente los países occidentales dejaron crecer ideologías anticomunistas, pero también surgidas en el contexto de lo que hemos llamado de la inversión sociológica, como el fascismo y el nazismo, que ponían por delante ideas supremacistas o idealistas de nación y tradición frente al comunismo. Se estranguló el movimiento obrero como se pudo y se desvió a la sociedad hacia ideales fascistas que alimentaron la maquinaria de guerra. La amenaza de Hitler creció con la complacencia occidental ante la expectativa de que Alemania del Tercer Reicht cumpliera los proyectos contra la URSS codificados en Mein Kampf. Como dice Alexander Zinoviev:

"Durante la segunda guerra mundial, los dirigentes de los países occidentales lograron dirigir la agresión alemana contra la Unión Soviética, pero este intento de destruir el país militarmente con la maquinaria bélica nazi también fracasó." (pág. 82).

Así pues, podemos decir que la II Guerra Mundial nació como consecuencia de la Revolución rusa en el seno de la inversión sociológica por la que la idea de Estado se convierte en el principal problema filosófico. 
El ortograma de la Unión Soviética es, por tanto, la racionalización sistemática de los excedentes productivos en todas las esferas de la producción, aplicado a la agricultura, la industria, el arte, la ciencia, y todas las dimensiones de la productividad humana. Racionalizar para conseguir el máximo rendimiento y gestionarlo a su vez. Pero esa racionalización no se entiende de modo estrictamente económico, liberal (lo que Zinoviev llama con razón el "totalitarismo monetario"). No se trata de alcanzar el máximo beneficio económico particular, sino el beneficio social. En este sentido Zinoviev decía:

"Hay dos maneras de abordar la actividad productiva de personas y empresas: la económica y la social. La organización de la actividad productiva de una sociedad, y en general de su vida práctica, no siempre se lleva a cabo con arreglo a los principios de la economía. Los criterios dictados por la ciencia económica se basan en la relación recíproca entre gastos y resultados de una actividad determinada. Los criterios sociales, en cambio, se basan en la media en que la actividad de la empresa responde a los intereses de toda la sociedad." (pag. 59-60).

Esto es lo que Gustavo Bueno, en su histórico discurso a los mineros asturianos el día 28 de junio de 1991, reprochaba a los políticos del PSOE que se dedicaron a desmantelar en entramado productivo industrial de la capa basal de España durante lo que llamaron con eufemismo "la reconversión industrial": que más allá del rendimiento económico estaba el rendimiento social. No hay más que darse una vuelta por las cuencas mineras asturianas para hacerse cargo de la debacle producida por el liberalismo economicista radical de la reconversión. Regiones enteras abandonadas, destruidas, y moralmente derrotadas. -Gracias, políticos. Claro que algunos dirán que esto no era rentable, que era una ruina, y tonterías por el estilo, pero hay que reconocer que si una guerra mundial y una guerra fría se dedicaron a derrotar a la URSS es porque su sistema económico no era tan suficientemente nefasto como para hundirse por sí mismo, en cuyo caso nunca hubiera sido necesario hacer acopio de tantos esfuerzos y gastos.

4. El éxito de la URSS en la Guerra Mundial hizo que el resto de los países se dividieran definitivamente en dos grandes bloques, lo cual es, sin duda ninguna, una de las más notables consecuencias de la Revolución de Octubre. Es curioso que Bernal, en la introducción a su Historia de la ciencia afirmara la tesis de que existen dos mundos, el mundo Comunista y el mundo Capitalista, añadiendo además otro "tercer mundo", definido no en función del estado de desarrollo de su capa basal -como hizo el economista francés Alfred Sauvy, que es como se suele entender hoy, sino más bien en términos civilizatorios y culturales, por lo que este tercer mundo viene identificado como el mundo Hispanoamericano, para Bernal perfectamente distinguible de los otros dos, y con mucho fundamento, diríamos nosotros, pues al menos durante todo el período del Imperio español hasta la época de Carlos III, el 
régimen católico basado en el Concilio de Trento excluía el lucro y regulaba los excedentes productivos mediante una intervención sistemática y decidida del estado a través de sus múltiples instrumentos administrativos, lo que dejó un perfil de naciones ostensiblemente diferenciadas. Ciertamente, la clasificación de Bernal tiene que ver simplemente con el hecho de que el bloque capitalista fundamentalmente vendría representado de modo ostensible por los países del mundo anglosajón.

La concreción de los dos bloques tuvo lugar tras la Segunda Guerra Mundial, cuando se vio que ni la locura hitleriana había sido capaz de derrotar a la Unión Soviética, como claramente se esperaba. Este es otro de los grandes éxitos objetivos que deben atribuirse a la Unión Soviética: la derrota del nazismo. Y negar esto ya forma parte de la leyenda negra contra la URSS, pero eso es otro asunto. Sobre la leyenda negra aplicada a la URSS cabe referir el magnífico libro de Doménico Losurdo sobre Stalin cuya lectura se hace necesaria.

Pero además de los dos grandes bloques fueron surgiendo también los llamados "países no alineados", que desde una clasificación basal serán luego en general identificados como "países en vías de desarrollo", surgidos de las luchas antiimperialistas y de los procesos de descolonización. Estos países siguieron una vía socialista pero no estrictamente comunista, y constituyeron un importante frente para el despliegue de la intervención política internacional de la Unión Soviética. De hecho, una vez que cayó el muro de Berlin en 1989 y la URSS en 1991, a consecuencia de la radicalización de las protestas en los países estrictamente comunistas del otro lado del Telón de Acero y que fueron barridos por oleadas neoliberales derivadas de un integración fatal en el contexto estratégico del Fondo Monetario Internacional, todavía permanecieron en pie los países no alineados marcando una pauta diferente que además de tener nacionalizados sectores productivos clave como el petróleo, seguían una política económica ajena a los dictados del Fondo Monetario Internacional y del Banco Mundial. Estos países son los que, una vez derrotado el bloque soviético, hubieron de ser demolidos paulatinamente, uno por uno, por la acción combinada de la Unión europea y de los ejércitos de la OTAN, como ocurrió con Yugoslavia, Irak, Egipto, Argelia, Afganistán, Cuba, Irán, Siria, Libia, etc. La demolición implacable de estos residuos que han hecho de algún modo frente al FMI ha sido en gran medida la política imperial norteamericana de la globalización, tratando de homologarlos a las democracias occidentales, aun a costa de que sus poblaciones acaben pereciendo en las profundidades del Mediterráneo intentando alcanzar esa Europa que no les ha permitido vivir de un modo diferente.

Así pues, podemos decir que incluso después de la debacle de la URSS en 1991 la política internacional ha venido marcada por el sistemático desmantelamiento de todos los vínculos que pueden quedar con los restos de aquel proyecto salvo la presencia inevitable de la Revolución maoísta, fruto también del marxismo y que hoy sostiene, como no podía ser de otra manera, al país más poderoso y con mayor potencial en el mundo: China. Porque no podemos olvidar, aunque algunos así lo pretenden debido al hecho de que hoy ya cuesta mucho tragarse los mitos antichinos, que China es hoy un país donde gobierna un único partido: el Partido 
Comunista Chino y lo hace porque en la mayor ofensiva de Occidente contra China en el contexto de la crisis del sureste asiático que integró a la mayor parte de aquellos territorios en el dictado del FMl, China no se plegó, como nos recuerda Stiglitz en su magnífico libro El malestar en la globalización, y hubo de sofocar Tiananmen. Gracias a haber parado ese golpe de 1989, y debido a la gestión estatal de los excedentes productivos, el país es hoy el más próspero de la tierra, sin discusión. La URSS se plegó a la ofensiva neoliberal y se entregó al FMI, arrasando con gran parte de la capa basal del estado soviético que quedó descompuesta en nuevos estados probando con ello que en efecto se trataba de un imperio generador, como lo fue el Romano, o el Español.

Pero las políticas del FMI aplicadas por el insensato Boris Yeltsin dejaron una devastación difícil de imaginar para un soviético medio. Esto ha sido reconocido de modo magistral por la autora Naomi Klein en su trabajo La doctrina del shock. En el magnífico libro sobre Limónov de Carrière se pone de manifiesto esta terrible contradicción entre unas aspiraciones de Perestroika y aperturismo planteadas en términos ajenos a la dialéctica de estados que era lo que estaba detrás verdaderamente empujando a la URSS hacia el desastre. Cuando Limónov regresó a Rusia después de haber abandonado el Járkov soviético, se encontró con que ninguna de las aspiraciones que alimentaban la protesta en la URSS se había cumplido, sino que todo había sido derribado, arrasado. Más sangrante, si cabe, es el caso del filósofo ruso Alexander Zinoviev, en el libro que hemos citado aquí abundantemente, La caída del imperio del mal, En él, este antiguo disidente soviético se acaba convirtiendo en un nostálgico de la URSS, reconociendo que efectivamente hicieron con su disidencia un flaco favor a su propio país, contemplando las desastrosas consecuencias de su caída. Lo mismo ocurre incluso con Zhores y Roy Medvedev, anteriormente disidentes soviéticos muy reconocidos y reputados en Occidente, que a la postre acaban tratando de reivindicar, con mucho acierto, por otra parte, la figura de Stalin en la Unión Soviética y la traición de Jruchov que abrió el camino a la disidencia "indefinida". Todos ellos han sufrido el espejismo anarquizante de la crítica radical de izquierda indefinida de estirpe occidental, hasta que vieron lo que pasaba con su país, entonces, más o menos han comprendido en profundidad lo que fue verdaderamente la política de la URSS inaugurada por Stalin. Algo que se ha puesto de manifiesto también en otros magníficos trabajos como el citado de Losurdo, o el magistral libro sobre Stalin escrito por el español Anselmo Sánchez, Stalin el grande (ed. Ehdasa).

Por tanto, podríamos decir que en la propia ideología marxista que alimentaba los ideales comunistas de la URSS cuyo fundamento es la lucha de clases, y que da por hecho que el Estado es una superestructura que es necesario superar en las aspiraciones comunistas hacia la sociedad sin clases, se alimentaba la idea de menospreciar la importancia de la dialéctica de estados que sin embargo estaba marcando sistemáticamente la agenda institucional y política de la URSS; mientras que la ideología orientaba la disidencia soviética hacia una postura que desde el Materialismo filosófico de Gustavo Bueno podríamos considerar indefinida, ajena al Estado. En el fondo es la dialéctica entre Trotski y Stalin, aunque hasta los más críticos con Stalin reconocen que su gran propuesta de industrialización acelerada y de planificación sistemática de la economía estaba ya prevista en los trabajos de 
Trostki elaborados cuando aún no había caído en desgracia, en 1924. Isaac Deutscher, un acérrimo seguidor de Trotsky escribió lo siguiente a la muerte del gran estratega del siglo XX:

"Tras tres decenios, el rostro de la Unión Soviética se ha transformado completamente. Lo esencial de la acción histórica del estalinismo es esto: se ha encontrado con una Rusia que trabaja la tierra con arados de madera, y la deja siendo dueña de la pila atómica. Ha alzado a Rusia hasta el grado de segunda potencia industrial del mundo, y no se trata solamente de una cuestión de mero progreso material y de organización. No se habría podido obtener un resultado similar sin una gran revolución cultural en la que se ha enviado al colegio a un país entero para impartirle una amplia enseñanza." (Apud Losurdo, p. 14.)

Si Stalin apoyó entonces las críticas de Bujarin ello respondía a sus propias estrategias de poder, por lo que, cuando en 1928 se pone en marcha el primer plan quinquenal, Bujarin habría de quedar apartado del poder, tal y como lo señala E. H. Carr. Hay que tener en cuenta que una vez que Kruchov accedió al poder, el informe secreto del XX Congreso del PCUS vino a socavar de modo ostensible la propia seguridad nacional, porque es evidente que aquel informe respondía a intereses de EEUU, tal y como denuncia Losurdo.

5. De hecho, tomando una serie de estudios acerca del asunto, en distintos momentos históricos podremos ver con cierta claridad cómo ha ido evolucionando la imagen de la URSS y los detalles acerca del proceso en virtud del cual este país magnífico, impetuoso y sorprendente, se vino abajo de un modo tan inesperado y lamentable. De las primeras impresiones maravillosamente descritas por ejemplo en la recopilación de artículos de finales de los años veinte que constituye el libro de Joseph Roth, Viaje a Rusia, la descripción del aspecto cotidiano de los grandes cambios no sólo políticos, sino también sociales y existenciales que traía consigo el nuevo modelo político de la URSS, vistos por un periodista a pie de calle, o las maravillosas historias narradas por Steinbeck en su viaje con Capa por la URSS justo al final de la Gran Guerra Patria, nada queda ya en la actualidad. La maravillosa novela Arena pesada de Anatoli Rybakov recoge también ese panorama magnífico de transformación social y entusiasmo colectivo. Cuando, por ejemplo, el año 1946 E. H. Carr dictó una serie de conferencias dedícadas a la cuestión de qué ha aportado la Unión Soviética al mundo fodavía vivía Stalin, y la URSS acababa de derrotar a la Alemania nazi fascista. En este libro no hay ni rastro de la leyenda negra que abatirá definitivamente a la URSS en los medios de comunicación y en la opinión generalizada de Occidente sobre la Unión Soviética. Carr analiza de un modo analítico y con mucha claridad en qué aspectos se ha notado de modo ostensible la influencia de la revolución de octubre en Occidente, sin poner en duda en ningún momento su organización administrativa ni su ideología. Reconoce y analiza el sistema político como una democracia popular, admira el éxito de la planificación económica que considera la base de las 
estrategias de planificación que luego todos los países hubieron de asumir, pero más allá reconoce la importancia de una planificación socialista. En ningún momento discute ni deja sombra alguna acerca de la fortaleza ideológica, moral y política de un país que ha sido capaz de afrontar la titánica tarea de derrotar al fascismo y explica la evolución de las relaciones internacionales inauguradas por la Unión Soviética como el ejercicio de un sano y prudente patriotismo. Steinbeck y Capa viajaron también después de la guerra y describen con admiración el sorprendente esfuerzo de la población por recuperar la normalidad de la vida en un país que Alemania dejó absolutamente destrozado. Recuerdo el detalle de los niños saliendo de sus casas, convertidas en escombros, a la escuela, perfectamente vestidos, pero en fin.

Lo siguiente fue el XX Congreso del PCUS en el que Kruchov hubo de hacer todos los malabarismos retóricos imaginables en una operación conjunta internacionalmente orquestada para hundir la figura de Stalin con falsedades como puños, para conseguir fortalecer y casi evidenciar sin discusiốn la ideología de la izquierda indefinida que había criticado a la URSS por su estalinismo. El informe de Kruchov significó efectivamente el primer paso para la radicalización del humanitarismo cosmopolita liberal individualista que alimentó y consagró las izquierdas indefinidas que hoy planean por todo el mundo occidental haciendo el ridículo, como en España. Lo más paradójico y lamentable es que ahora, en el fragor de los patéticos debates políticos actuales, resulta que se acusa a estos partidos de izquierda divagante e indefinida, una conexión ideológica con la práctica política de la Unión Soviética, algo de todo punto absurdo y deleznable, pero es así como Roma paga a los traidores.

El informe Kruchov impregnó como una lluvia fina y persistente el imaginario ideológico de la intelectualidad europea y dejó paso a la aceptación acrítica y radical de cualquier discurso antisoviético. Las críticas de Solsenitsin, las autobiografías como la de la hija de Stalin, o la de la mujer de Bujarin, los relatos circunstanciales y particulares que insisten en el sufrimiento particular alimentando la idea de un poder abusivo y absurdo, ocultan de hecho el contexto de conflicto ideológico que se lidiaba en la Unión Soviética, y han contribuido abiertamente a la crítica radical indefinida occidental, incluyendo premios Nobel de la paz, incluso para el gran disidente Sajarov, quien creó la bomba de hidrógeno. Todo esto fue minando la propia solidez ideológica y la sensatez del proyecto que hubo de ser traicionado por las propias élites políticas, como señala abiertamente Zinoviev para que se hundiera, porque incluso un referéndum organizado por Gorbachov había sido ganado claramente por los partidarios de conservar la Unión Soviética, algo que Yeltsin ignoró deliberadamente aprovechando el nacionalismo ruso: un ejemplo de los muchos que muestran cómo Occidente valora a su modo el uso de los referenda; como en Grecia, etc.

No podemos dejar de mencionar la eficaz serie de tópicos perfectamente preparada por Kapuchinski en su existoso libro Imperio, echando abajo la URSS con gruesas y eficaces pinceladas. Cuando Zinoviev escribió El fin del imperio del mal, muy pocos nos atrevíamos a reconocer validez a la tesis de la traición interna a la Unión Soviética, una traición que se fragua con el informe Kruchov y que está 
avalada por muchos estudios, como el de Sergei Karamourza sobre el estado económico de la URSS justo antes de su caída. Pero después del golpe de estado de Yeltsin, amparado por Occidente en 1993, y la entrega al FMl, no cabe duda de que el asunto se había fraguado abiertamente desde las élites del poder, lo que demuestra también la poca solidez del sistema. Estas tesis, ya vistas con más perspectiva histórica han quedado definitivamente explicadas con todo lujo de detalles, sorprendentes e indignantes, en la magnífica revisión realizada por el historiador italiano Doménico Losurdo, que ha cerrado definitivamente, a mi entender, el debate histórico acerca del fin de la URSS.

De hecho, lo que hace Losurdo, esto es, desmontar la leyenda negra de Stalin, es terminar definitivamente con las críticas que la izquierda indefinida han dedicado a la URSS y con los propios fundamentos ideológicos de la izquierda indefinida, cosa que resulta de todo punto imposible mediáticamente porque Stalin está siendo juzgado y sentenciado cada día como si de una sombra persistente se tratase, un fantasma. Más allá de su valor como ensayo de Historia, está el hecho de que arrastra tras de sí a todos los partidos que desde la izquierda se han conformado con la ideología antisoviética y antiestatalista y por ello este libro de Historia nunca será reconocido por quienes deberían estudiarlo a fondo. El libro de Losurdo pone de manifiesto que Stalin es la piedra de toque de la legitimación del proyecto soviético. Empezó a traicionarse el proyecto desde dentro luchando contra Stalin como expresión del socialismo en un sólo país y de ahí se pasó a considerar el propio comunismo como un modelo político ineficaz, y fracasado, en la medida en que la URSS ha sido destruida. Sin embargo, lo curioso es que aun cumplidas todas las expectativas de Occidente, la guerra fría perdura y ha adquirido una nueva forma en la Rusia de Putin, poniendo de manifiesto una idea que está también recogida en el libro de Zinoviev, según la cual la guerra fría no era contra el comunismo sino contra la URSS. "Apuntaban al comunismo, y mataron a Rusia" (p. 88). porque el peligro era y sigue siendo, para Occidente, cualquier estado organizado racionalmente en la gestión de los recursos desde una perspectiva socialista.

Chipiona, 26 de agosto de 2017 